\title{
LEGENDAS E JANELAS: QUESTÃO DE ACESSIBILIDADE
}

\author{
SUBTILES AND SING LANGUAGE INTERPRETER: \\ ACCESSIBILITY QUESTION
}

SUBTÍTULOS Y VENTANAS: CUESTIÓN DE ACCESIBILIDAD

Núbia Guimarães Faria *

Daniel Carvalho Silva ${ }^{* *}$

\section{Resumo}

Em consonância às leis que contribuem com o direito dos surdos ao acesso às mídias televisionadas, este trabalho se propõe a refletir sobre o processo de recepção e compreensão dos surdos em relação aos programas televisivos e identificar suas preferências entre programas que apresentam legendas e os que têm janelas com intérpretes de Língua Brasileira de Sinais (Libras). Esse problema se coloca a partir do anseio da comunidade surda por ter respeitados seus direitos de acesso à cultura, ao lazer e a arte midiatizados por canais audiovisuais, que, em sua maioria, não disponibilizam legendas nem janelas. Ademais, buscase evidenciar aspectos que contribuiriam não somente para o acesso, mas também para a aquisição da língua portuguesa e mesmo da Libras pelos surdos. Com o intuito de levantar uma amostra sobre o que surdos e intérpretes pensam sobre essas questões, foram aplicados dois questionários, o primeiro aos surdos e o segundo aos intérpretes de Libras. Este trabalho apresenta o resultado dessa pesquisa, feita a partir das informações coletadas nos questionários.

Palavras-chave: legendagem, janelas para intérpretes de Libras na TV, acessibilidade.

"As leis não bastam. Os lírios não nascem da lei."

Carlos Drummond

Em dezembro de 1978, foi promulgada a Lei $\mathrm{n}^{\circ}$ 6.606, a primeira no Brasil a exigir das emissoras de televisão a inserção de legendas em língua portuguesa na exibição de filmes estrangeiros. $\mathrm{O}$ segundo passo legal rumo à acessibilidade visual aos programas televisivos foi dado pelo Tribunal Superior Eleitoral (TSE) em setembro de 1994. A Resolução do TSE

\footnotetext{
* Graduação em Pedagogia e em Letras-Libras pela Universidade Federal de Santa Catarina - UFSC. Professora do curso de Letras: Libras da Universidade Federal de Goiás - UFG. E-mail: núbia.letras.ufg@ gamail.com.

** Graduação em Filosofia (IFITEG) e em Letras: Libras pela Universidade Federal de Goiás - UFG. Professor da Universidade Estadual de Mato Grosso - UNEMAT. E-mail: carvalho_danyel@ hotmail.com
} 
$\mathrm{n}^{\mathrm{o}} 14.550$, determinava que a janela com intérprete de Libras fosse obrigatória para todas as divulgações oficiais e televisionadas do tribunal, bem como às propagandas eleitorais dos partidos políticos. Somente em novembro de 2000 foi publicada a Lei $\mathrm{n}^{\mathbf{0}} 10.098$, que estabeleceu normas gerais e critérios básicos para a promoção da acessibilidade de pessoas portadoras de deficiência. O artigo 17 do VII capítulo dessa lei prevê que o poder público deverá trabalhar em prol da eliminação de barreiras na comunicação e que estabelecerá mecanismos e alternativas de comunicação e sinalização "às pessoas portadoras de deficiência sensorial e com dificuldade de comunicação para garantir-lhes o direito de acesso à informação, à comunicação, ao trabalho, à educação, ao transporte, à cultura, ao esporte e ao lazer”. Essa foi a primeira lei a tratar especificamente a questão da acessibilidade dos surdos à mídia televisiva, entretanto, sem detalhar os meios de acesso a serem utilizados.

Quatro anos depois, o Decreto da presidência da república $\mathrm{n}^{\circ} 5.296$, de dezembro de 2004 regulamentou a Lei $n^{\circ} 10.048$, de 8 de novembro de 2000, que dá prioridade de atendimento às pessoas que com deficiência, idosos e gestantes, e a Lei $\mathrm{n}^{\circ} 10.098$, de 19 de dezembro de 2000, que estabelece normas gerais e critérios básicos para a promoção da acessibilidade das pessoas deficientes ou com mobilidade reduzida, que prevê no incisos I e II do $2^{\circ} \S$ do artigo 53 a "subtitulação por meio de legenda oculta" e "a janela com intérprete de Libras”. A partir de então, tornou-se possível a existência da legenda oculta (Closed Caption) e da janela de intérprete de Libras no Brasil, sob a regulamentação do Ministério das Comunicações, que aprovou, em 27 de junho de 2006, a Portaria $\mathrm{n}^{\mathbf{0}}$ 310, que normatiza objetivamente a legenda e a janela de intérprete de Libras conferindo às pessoas surdas o direito de acesso às informações e entretenimentos televisivos.

Dada a realidade legal, é preciso reconhecer os avanços, mas é possível e necessário também elencar os problemas ainda encontrados pelos surdos em seus meios de acesso à mídia televisiva. Esses meios são veiculados somente pelos canais governamentais e por grandes empresas, como a Rede Globo e o Sistema Brasileiro de Televisão (SBT), embora não estejam disponíveis para toda a programação e nem para os comerciais, que não apresentam legendas nem janela de Libras. Além do mais, por serem digitadas simultaneamente à exibição, as legendas apresentam erros de português, o que dificulta ainda mais para os surdos que, em geral, não dominam bem a língua portuguesa. Por outro lado, as janelas para intérpretes, em geral, são pequenas e isso dificulta a visão e a compreensão dos sinais. 
Tais fatores atestam o fato de que o acesso dos surdos aos programas televisivos ainda é muito limitado e, por essa razão, acreditamos que o tema carece ser investigado. Este artigo propõe avaliar questões que envolvem o uso de legendas e janelas nas produções televisivas, levantar as preferências dos surdos no que diz respeito ao uso de legendas em português e de janelas com a interpretação em Libras, avaliando os contingentes que perpassam tais preferências. Para isso, faz-se necessário que definamos e esclareçamos o que são legendas e o que são janelas de intérpretes.

De acordo com a Portaria $n^{\circ}$ 310, de junho de 2006, do Ministério das Comunicações, o termo "legenda" pode seu compreendido como a "transcrição, em língua portuguesa, dos diálogos, efeitos sonoros, sons do ambiente e demais informações que não poderiam ser percebidos ou compreendidos por pessoas com deficiência auditiva”. De acordo com Vigata e Barbosa (2009) as legendas são uma forma de acessibilidade, já que transcrevem as palavras emitidas oralmente; isso constitui um processo de tradução intralingual, ou seja, a alteração ocorre apenas no código de emissão da mensagem, antes oral, agora escrito, e todo o processo se dá em uma mesma língua. Mas a legenda pode também constituir um meio de tradução de língua, utilizada, por exemplo, em exibições de filmes estrangeiros. Neste caso, a tradução é interlingual, já que traduz uma língua oral para outra língua em modalidade escrita. A tradução interlingual, ao contrário da intralingual, só pode ocorrer entre duas línguas ou mais, nunca em uma única língua. Para o segundo caso, vale a síntese de Heloisa G. Barbosa sobre as três prioridades elementares da tradução:

1) redução do texto original a seus núcleos (...) mais simples e semanticamente mais evidentes. 2) transferência do significado da LO [língua original] para a LT [língua de tradução] em um nível estruturalmente simples e 3) geração de uma expressão estilística e semanticamente equivalente na língua da tradução (1990, p. 33).

Segundo Araújo (2006), a legenda fechada e a legenda aberta são os tipos mais comuns utilizados no Brasil. A legenda aberta, também conhecida na indústria audiofonográfica como "legendagem", é editada junto ao vídeo, aparece sobreposta à imagem e não permite ser ocultada. A fechada (Closed Caption ou CC), geralmente é utilizada em programas televisivos exibidos ao vivo e são digitadas simultaneamente à fala. Esse tipo de legenda não permite correções no texto e pode ser acionada pelo controle remoto do televisor ${ }^{1}$. As letras, geralmente brancas, aparecem sobre tarjas pretas. 
A legenda fechada se divide em dois tipos (ALMEIDA et al, 2011): o Roll-up (rotativo) e o Pop-on ou Pop-up (blocos). No primeiro, há duas linhas onde as palavras sobem continuamente, surgindo da esquerda para a direita. No segundo, a exibição se dá por frases ou sentenças completas que ficam expostas por determinado tempo até serem trocadas. Nesse processo é utilizada uma máquina de taquigrafia computadorizada, que relaciona um sinal gráfico ao som da voz humana. As teclas dessa máquina, segundo Lima e Rossel (1977), são chamadas "estena" (termo grego que significa "estreito", "escrita escondida, cifrada", “mensagem secreta”). Estas teclas são comparáveis às letras do alfabeto arábico, no entanto, na estenotipia, tem-se somente 24 teclas para a digitação de qualquer palavra, seja acentuada ou composta. O número de teclas é reduzido com o intuito de imprimir mais rapidez à digitação. No entanto, a rapidez pretendida e necessária na digitação acarreta alguns problemas. Os erros ortográficos, frequentemente exibidos nas legendas ocultas, são exemplos disso. Em geral, as duas maiores dificuldades encontradas pelos surdos na leitura das legendas são os erros ortográficos e os atrasos na digitação ou omissão das informações, além disso, o português digitado obedece a estruturas orais, não formais, o que agrava a dificuldade de compreensão.

Em abril de 2004, Marcelo de Carvalho Pedroso, um pernambucano surdo, participou, com alguns amigos, do Festival Audiovisual de Pernambuco (CINE-PE), na cidade de Recife. Sentindo-se excluído, por não poder acessar o áudio dos filmes nacionais, começou a mobilizar amigos e parentes para o fato. No último dia do evento, no dia5 de maio, cerca de cem pessoas foram ao Centro de Convenções do Pernambuco para apoiar a causa. Nasceu, então, a campanha "Legenda Nacional" com o lema "Legenda, para quem não ouve, mas se emociona". Da campanha surgiu o site: www.legendanacional.com.br, com aporte para abaixo-assinado.

O objetivo da campanha foi conscientizar a comunidade surda sobre seus direitos e alertar o poder nacional e as produtoras de vídeo sobre a necessidade do acesso de todas as pessoas à cultura veiculada pela mídia televisiva, como prevê a lei $\mathrm{n}^{\circ} 10.098$, de 2000. Dessa campanha surgiu também um Projeto de Lei Federal, de no 1.078/2007 que, se aprovada, obrigará as distribuidoras de filmes e os organizadores de exibições de peças teatrais a legendar as obras exibidas ou a oferecer interpretação do texto correspondente.

A portaria $\mathrm{n}^{\mathrm{o}} 310$, de 28 de Junho de 2006, do Ministério das Comunicações, define a Janela de Libras como um "espaço delimitado no vídeo onde as informações são interpretadas na Língua Brasileira de Sinais”. Este meio de acesso à informação exige a presença e o 
desempenho de um profissional que faça a mediação entre os discursos emitidos e os sujeitos que os recebem, de modo a significar o primeiro e tornar sua compreensão possível ao segundo. De acordo com Marcus V. B. Nascimento (2012, s/p):

\begin{abstract}
A tradução/interpretação da Libras/Português/Libras caracteriza-se em um ato enunciativo de mediação discursiva de dois indivíduos organizados socialmente: um locutor que enuncia em uma das línguas em um determinado momento e contexto histórico inserido em uma esfera ideológica; e um interlocutor que é auditório social do enunciado produzido pelo locutor que também está inserido em um momento e contexto histórico e que também faz parte de uma esfera ideológica. O intérprete de Libras, nesse caso, é o sujeito responsável pela mediação enunciativa da interação discursiva entre os falantes dessas línguas.
\end{abstract}

O intérprete é a ponte entre o discurso de um e a surdez de outro. No entanto, muitas vezes, essa ponte em janelas televisivas pode ser prejudicada por alguns motivos. Um deles refere-se ao tamanho da janela, pois se for muito pequena, não permite o entendimento das palavras digitadas ou dos sinais (observe-se que o tamanho da janela varia também conforme o tamanho do aparelho televisor). Outro motivo é o de não haver interação ou comunicação anterior entre intérpretes e organizadores dos programas, de modo que os intérpretes só têm conhecimento do conteúdo a ser interpretado no momento da interpretação. Em geral, isso resulta em traduções que fogem ao tema, bem como em perdas causadas pelo revezamento dos intérpretes. Há ainda o fato de, em casos de programas exibidos em rede nacional, serem usados sinais desconhecidos em determinadas regiões, o que caracteriza inadequação entre a linguagem utilizada e seu público alvo.

De acordo a Associação Brasileira de Normas Técnicas (ABNT, 2008, p.40) a altura da janela deve ter, no mínimo, metade da altura da tela do televisor e a largura deve ocupar no mínimo a quarta parte. De acordo com Flávia O. Machado (2011), a fiscalização do cumprimento dessa regulamentação é de responsabilidade conjunta do Ministério das Comunicações da Agência Nacional de Telecomunicações (ANATEL). Contudo, não há ampla e clara divulgação acerca da quantidade de programas que disponibilizam legendas ocultas veiculadas nas transmissões tanto analógicas quanto digitais, de forma que a existência ou não da legenda, fica sob responsabilidade e opção das redes transmissoras.

Em termos de acessibilidade, a falta de legendas ou janelas com intérpretes de Libras, bem como a não existência de áudio-descrição, na maioria dos filmes nacionais, revela o descaso com as minorias. No entanto, há outras intersecções que merecem atenção. Amanda 
C. Assis (2011) relata a dificuldade em se utilizar um filme nacional legendado em uma sala de aula de ensino fundamental. Segundo a autora, os alunos surdos não dominavam a língua portuguesa a ponto de poderem acompanhar a legenda tal como estava escrita. Como não havia janela de intérpretes, pensou-se na possibilidade de duas profissionais fazerem a interpretação simultaneamente ao filme. No entanto, o colégio não dispunha de duas intérpretes por sala de aula em um mesmo horário. Pensou-se então em gravar a interpretação e exibi-la numa TV ao lado do filme. Mas, além de não ser possível aos alunos surdos assistirem as duas TVs, a própria escola não dispunha de dois aparelhos para uma mesma aula. Ademais, devido à duração do filme e ao grande número de vozes presentes nele, seria muito cansativo para uma intérprete sozinha fazer toda a narração. Por outro lado, a troca de intérpretes no meio do filme poderia causar uma quebra na interpretação. Optaram então por fazer a gravação com as duas intérpretes no mesmo vídeo e editaram o filme de modo a inserirem a janela com as duas intérpretes nele, o que, dentre todas as opções, pareceu a melhor.

O fato narrado expressa claramente a verdade linguística de que o processo de compreensão não depende unicamente da existência da mensagem, mas também e em mesmo grau de importância, do receptor. Conforme Serra (2007), é preciso levar em conta o domínio que o receptor tem da língua em que a mensagem é transmitida, bem como as questões subjetivas e as relações linguístico-cognitivas que o sujeito-alvo da mensagem emitida é capaz de estabelecer. Portanto, para além da existência ou não da legenda ou da janela com o intérprete, é preciso pensar seriamente sobre a mensagem que se transmite e se ela, de fato, é capaz de expressar aquilo a que se propõe.

Para que os objetivos propostos para esta pesquisa fossem alcançados, foram aplicados dois questionários distintos e objetivos: um deles destinados aos surdos ${ }^{2}$, com oito perguntas, e o outro a intérpretes de Libras, com sete ${ }^{3}$. Foi preciso entrevistar surdos e intérpretes, pois era necessário compreender como a janela era recebida pelos surdos como era produzida pelos intérpretes. Foram entrevistados oito surdos e oito intérpretes. Os surdos, todos alunos do curso de Letras: Libras da Universidade Federal de Goiás (UFG) e do Centro Especializado Elysio Campos, uma escola bilíngue, mantida pelo Governo de Goiás, e locada no prédio da Associação de Surdos de Goiânia (ASG). A entrevista foi feita em LIBRAS, filmada e posteriormente transcrita. Dos oito intérpretes entrevistados, três são do Centro de Capacitação de Profissionais da Educação e Atendimento às Pessoas com Surdez (CAS), quatro do curso de Letras: Libras da UFG e um que atua na TV Câmara, durante as Sessões 
Plenárias Ordinárias da Câmara dos vereadores de Goiânia.Este último foi o único profissional encontrado com experiência em TV na capital goiana.Tal fato evidencia que o mercado de trabalho para profissionais tradutores/intérpretes de programas televisivos é muito pequeno, o que, por si só, denota a baixíssima utilização de janelas para intérpretes em programas televisionados produzidos em Goiânia. No caso, o intérprete havia sido contratado como estagiário e trabalhava sozinho, sem revezamento e intérprete de apoio. Salienta-se ainda que as plenárias televisionadas da câmara dos vereadores só ganharam tradução/interpretação para Libras por exigência judicial do Ministério Público do Estado de Goiás (MP-GO).

De acordo com seis dos intérpretes entrevistados, a janela para intérprete realiza melhor a função a que se propõe. Entre os motivos elencados por eles, e aqui transcritos, o primeiro é que "a janela permite uma tradução que transmite o sentido em Língua de Sinais em uma visão voltada para os surdos" enquanto a legenda "transmite as falas dos personagens, transcreve os sons apresentados em uma perspectiva realista, trazendo sentido na língua portuguesa - que não é a língua dos surdos”. Outro motivo, segundo os entrevistados, é que "o intérprete conhece as particularidades dos surdos. A legenda não está na língua natural do surdo e, com sua imensa dificuldade com o português, tem dificuldade de compreensão". Outro intérprete afirma que "a janela utiliza a L1, que é a primeira língua dos surdos, e isso facilita a compreensão". Um dos intérpretes entrevistados afirmou que a comunicação “depende da fluência do surdo em Língua Portuguesa e mesmo em Libras", entretanto, ressaltou que "a legenda precisa melhorar o nível linguístico (...) e a janela precisa ser um pouco mais visível".

Entre os argumentos repetidos por quase todos os intérpretes entrevistados estão os seguintes: "a janela é melhor por ser a língua natural dos surdos”;“o surdo não domina completamente a língua portuguesa"; “a janela representa respeito à Libras".Apenas um entrevistado afirmou que a Legenda seria melhor, uma vez que "a Janela sempre apresenta falhas de visualização e compreensão", enquanto a legenda "engloba toda a língua portuguesa".

A pesquisa feita com os surdos revelou outros aspectos, como o fato de os programas eleitorais terem sido, como previsto em lei, os primeiros a utilizar a janela para intérpretes, já que quatro dos entrevistados afirmaram ter assistido a um programa com tradução / interpretação para LIBRAS pela primeira vez em propagandas eleitorais gratuitas. A legenda foi vista por eles pela primeira vez em filmes, novelas e jornais exibidos pela Rede Globo. 
Quanto à preferência entre janela e legenda, seis entrevistados surdos optaram pela legenda. Entre os motivos expostos estão os seguintes: "para mim é muito mais clara do que a janela, pois a janela me atrapalha ver o resto da tela"; "a legenda me ajuda a aprender palavras novas do português e isso é muito importante"; "a janela de intérpretes é muito pequena, então, como sei bem o português, prefiro a legenda"; "não consigo ver a imagem da TV e a imagem do intérprete ao mesmo tempo. Mas consigo ler a legenda e ver a imagem da TV ao mesmo tempo, então, mesmo que eu não entenda algumas palavras em português, compreendo todo o contexto"; "a legenda informa que existem sons, como música, trovões, gritos longe, muitas pessoas conversando, aplausos... paralelos à fala, coisas que um intérprete sozinho não consegue traduzir".

Tamanha aceitação da legenda por parte dos surdos atesta a capacidade de compreensão da língua portuguesa e de outras formas de expressão linguística que eles dominam e que, ao que parece, passam despercebidas aos olhos dos intérpretes. Segundo Sabine Gorovitz (2006), questões práticas e técnicas justificam as deficiências da legendagem, mas o espectador interfere com seu potencial subjetivo, que promove as necessidades de interação, compensando tais deficiências. Sobre as legendas ocultas, Gorovitz afirma que "o receptor atua por correspondência, tirando de seu próprio léxico cultural os elementos que não estão explicitamente sugeridos (...) assim como aqueles que escapam à tradução" (2006, p.23). Além disso, como pontua Gomes, a legenda age como motivador e promotor de melhoras na habilidade de leitura, já que desafia o telespectador a identificar rapidamente as palavras-chave e a associar palavras e imagens (2006, p.33).

Os outros dois surdos entrevistados afirmaram que, como as duas opções são boas, embora falhas, eles afirmaram preferir as duas: “às vezes a legenda passa muito rápido, há palavras que não entendo e isso não permite a leitura perfeita, da mesma forma que a janela muitas vezes é filmada de longe, o intérprete parece formiga, tem sinais muito diferentes e a datilologia fica incompreensível”; “eu tenho pouco domínio da língua portuguesa, mas também tenho muita dificuldade de enxergar todos os sinais exibidos na janela de intérpretes". Conforme o relato da maioria, o déficit de compreensão que por vezes ocorre é sempre sanado em diálogo com outra pessoa, surda ou não. Prova disso é que os surdos não estão isentos dos modismos, em geral ditados pelas novelas, tampouco dos temas de debates cotidianos, expostos nos telejornais.

André R. Reichert (2006) afirma que a escolaridade do surdo influencia diretamente em sua compreensão dos conteúdos televisionados. Segundo ele, os surdos que dominam a 
língua portuguesa tendem a preferir a legenda, enquanto os surdos que dominam melhor a Libras preferem a janela com intérprete. Ambos - legenda e janela - apresentam fatores positivos e negativos em seus aspectos essenciais, mas o fato é que ambos carecem melhorias. Por exemplo, a janela com o intérprete possibilita o aumento e a padronização do léxico da Língua de Sinal utilizada em todo o país, bem como o uso da legenda possibilita a aquisição e apropriação da língua portuguesa pelas pessoas surdas, ainda que a primeira, a princípio, possa apresentar sinais incompreensíveis, e a segunda, não ser apresentada na norma culta do português, com muitos erros ortográficos e palavras desconhecidas.

O que se espera, para um futuro próximo, são melhorias, como resposta à militância da comunidade surda, unida à de todos os profissionais que trabalham com surdez, em marcha pela gestação e efetivação de políticas públicas comprometidas com a causa surda que, dentre outras coisas, trata a questão da acessibilidade. Os surdos sempre compreenderam o mundo pelos olhos, e isso se aplica também à TV, mesmo quando não há legendas ou interpretações.

As crianças surdas se interessam pelos desenhos animados sem falas tanto quanto as crianças ouvintes e, nestes casos, as legendas não contribuiriam em nada, já que a aquisição do português por crianças surdas deve ser aprendida posteriormente à Libras, que é sua língua natural. No entanto, os desenhos animados contribuem com a construção do imaginário da criança, o que se soma de forma nítida à sua cosmovisão, tão necessária para o desenvolvimento cognitivo.

Com esta pesquisa, foi possível observar que, diferente do que se costumava presumir, os surdos, em sua maioria, preferem se lançar para fora de suas zonas de conforto a fim de aprenderem mais, de conquistarem autonomia linguística. Também desejam ter acesso mais facilitado às imagens televisionadas, já que a janela quase impossibilita assistirem o que se passa na TV. Tal fato abre a possibilidade de novas reflexões outras acerca do bilinguismo surdo, do assistencialismo e da "visão patológica" que ainda recai sobre o surdo. Por outro lado, é possível perceber muitas sementes germinando, florescendo e frutificando no nessa caminhada rumo à autonomia dos cidadãos surdos.

\footnotetext{
Abstract

In conformity with the laws that contribute to the right of deaf people to access to televised media, this paper aims to reflect on the process of receiving and understanding of the deaf in relation to television programs and identify their preferences between programs that have subtitles and those who have windows of Brazilian Sign Language interpreters (Libras). This problem arises from the desire of the deaf community for having respected their rights of access to culture, leisure and art midiatized by audiovisual channels, which mostly do not
} 
provide subtitles or windows. In addition, it seeks to highlight aspects that would contribute not only to access but also to the acquisition of the Portuguese language and even Libras by deaf. In order to get a sample of what deaf and interpreters think about these issues, they applied two questionnaires, the first to the deaf and the second to Pounds interpreters. This paper presents the results of this survey, conducted from the information collected in the questionnaires.

Keywords: subtitling, sing language interpreter in TV, accessibility.

\section{Resumen}

De conformidad con las leyes que contribuyen a la derecha de las personas sordas el acceso a los medios de comunicación televisiva, este trabajo tiene como objetivo reflexionar sobre el proceso de recepción y la comprensión de las personas sordas en relación con los programas de televisión e identificar sus preferencias entre los programas que tienen subtítulos y los que tienen Ventanas con intérpretes de Lengua de Signos brasileña (Libras). Este problema surge del deseo de la comunidad sorda por haber respetado sus derechos de acceso a cultura, el ocio y el arte a través de canales audiovisuales, que en su mayoría no ofrecen subtítulos o ventanas. Además, se pretende dar a conocer los aspectos que contribuyeron no sólo para el acceso, sino también a la adquisición de la lengua portuguesa e incluso Libras por sordos. Con el fin de obtener una muestra de lo sordos e intérpretes pensar en estos temas, aplicaron dos cuestionarios, el primero a los sordos y el segundo a Libras intérpretes. Este trabajo presenta los resultados de esta encuesta, realizada a partir de la información recogida en los cuestionarios.

Palabras-llave: subtitulado, ventanas para intérpretes de Libras, accesibilidad.

\section{Notas}

1. Ver mais informações sobre a história e os meios de exibição da legenda oculta em: INCLUDIGITAL: uma proposta de acessibilidade para deficientes auditivos e visuais na educação regular. Disponível em: <http://www.cin.ufpe.br/ 1sc4/snct2011/files/SNCTIFPE_0004.pdf>. Acesso em: $18 / 08 / 2013$.

2. Questionário aplicado aos Surdos

1-Você sabe LIBRAS desde que idade? Qual a sua idade atual?

2-Qual foi o primeiro programa de televisão, filme, telejornal ou outro... que você assistiu com a janela para intérprete? Que idade você tinha?

3-Você compreende bem a Língua Portuguesa? Sim ( ) Não ( ). Se sim, desde que idade?

4-Qual foi o primeiro programa de televisão, filme, telejornal ou outros... que você assistiu com legenda? Que idade você tinha?

5-Que diferença básica você percebe entre a legenda e a janela para o intérprete?

6-Qual te possibilita melhor compreensão? Por quê? 
7-Quais melhorias você poderia Sugerir?

8-Para você qual a importância sociocultural das informações e do entretenimento oferecidos pelos programas de televisão?

3. Questionário aplicado aos Intérpretes

1-Você é interprete de LIBRASa quanto tempo?

2-Já interpretou programas televisionados? Sim ( ) Não( ).

Somente para aqueles que responderam sim:

A-Durante quanto tempo (ou quantas vezes)?

B-Você assistiu sua interpretação? Sim ( ) Não ( ).

O tamanho da janela era satisfatório? Sim ( ) Não ( ). Por quê?

3- Que diferença básica você, enquanto profissional tradutor/intérprete de língua de Sinais, percebe entre a legenda e a janela com o intérprete?

4-Qual você acredita desempenhar melhor sua função de comunicação com os surdos?

Por quê?

5-Você destacaria alguma importância para os programas televisivos na educação dos surdos?

6-Sobre a acessibilidade dos surdos aos programas televisivos, você tem alguma sugestão de melhoria?

\section{Referências}

ALMEIDA, Marcos Souza et al. INCLUDIGITAL: uma proposta de acessibilidade para deficientes auditivos e visuais na educação regular. In: Semana Nacional de Ciência e Tecnologia do IFPE, 2., 2011, Caruaru. Anais eletrônicos... Caruaru: IFPE, 2011. Disponível em: 〈http://www.cin.ufpe.br/ 1sc4/snct2011/files/SNCTIFPE_0004.pdf〉. Acesso em: 6 jun. 2014.

ARAÚJO, Vera Lúcia Santiago. O processo de legendagem no Brasil. Fortaleza, Revista do GELNE, v. 1/2, n. 1, p. 156-159, 2006. Disponível em: <http://www.gelne.ufc.br/revista_ano4_no1_39.pdf>. Acesso em: 6 de jun. 2014.

ASSIS, Amanda Cristina de. A inserção de janela em língua de sinais em filme nacional e algumas consequências. PROFT em Revista, São Paulo, v. 1, n. 1, out. 2011. Disponível em: <http://www.proftemrevista.com/DOCS/V1/AmandaCristinadeAssis.pdf>. Acesso em: 21 abr. 2014.

ASSOCIAÇÃO BRASILEIRA DE NORMAS TÉCNICAS. NBR 15.604: Televisão Digital Terrestre: Receptores. Rio de Janeiro: ABNT, 2008.

BARBOSA, Heloisa Gonçalves. Procedimentos técnicos da tradução. Campinas: Pontes, 1990.

BRASIL. Decreto ${ }^{\circ} 5.296$, de 2 de dezembro de 2004. Regulamenta as Leis $n^{\circ} 10.048$, de 8 de novembro de 2000, que dá prioridade de atendimento às pessoas que especifica, e 10.098, de 19 de dezembro de 2000, que estabelece normas gerais e critérios básicos para a implementação da acessibilidade das pessoas portadoras de deficiência ou com mobilidade reduzida, e dá outras providências. Diário Oficial [da] União, Brasília, DF, 3 dez. 2004. 
Disponível em: <http://www.planalto.gov.br/ccivil_03/_ato20042006/2004/decreto/d5296.htm>. Acesso em: 16 abr. 2014.

Lei $\mathrm{n}^{\circ}$ 6.606, de 07 de dezembro de 1978. Obriga as emissoras de televisão a incluir, nas suas programações semanais de filmes estrangeiros, um filme, pelo menos, com legenda em português. Diário Oficial [da] União, Brasília, DF, 12 dez. 1978. Disponível em: <http://www.planalto.gov.br/ccivil_03/leis/1970-1979/L6606.htm>. Acesso em: 16 abr. 2014.

Lei $\mathrm{n}^{\circ} 10.048$, de 8 de novembro de 2000. Dá prioridade de atendimento às pessoas que especifica, e dá outras providências. Diário Oficial [da] União, Brasília, DF, 9 nov. 2000. Disponível em: <http://www.planalto.gov.br/ccivil_03/LEIS/L10048.htm>. Acesso em: 14 abr. 2014.

Lei $\mathrm{n}^{\circ} 10.098$, de 19 de dezembro de 2000. Estabelece normas gerais e critério básicos para a promoção da acessibilidade das pessoas portadoras de deficiência ou com mobilidade reduzida, e dá outras providências. Diário Oficial [da] União, Brasília, DF, 20 dez. 2000. Disponível em: <http://www.planalto.gov.br/ccivil_03/LEIS/L10098.htm>. Acesso em: 15 abr. 2014.

Ministério das Comunicações. Portaria no 310, de 27 de junho de 2006. Aprova a Norma $n^{\circ}$ 001/2006 - Recursos de acessibilidade para pessoas com deficiência, na programação veiculada nos serviços de radiodifusão de sons e imagens e de retransmissão de televisão. Disponível em: <http://www.mc.gov.br/portarias/24680-portaria-n-310-de-27-dejunho-de-2006>. Acesso em: 13 jul. 2010.

Projeto de Lei ${ }^{\circ} 1.078$, de 8 de abril de 2007. Dispõe sobre a adoção de legenda em filmes nacionais e em exibições de peças teatrais. Diário da Câmara dos Deputados, Brasília, DF, 7 jun. 2007. Disponível em:

<http://www2.camara.leg.br/proposicoesWeb/fichadetramitacao?idProposicao=351652>. Acesso em: 5 abr. 2013.

Tribunal Superior Eleitoral. Resolução no 14.550, de 1 de Setembro de 1994.

Autorização aos partidos políticos para utilização de intérpretes da linguagem de sinais no horário político gratuito de televisão. Disponível em:

$<$ http://www.presp.mpf.mp.br/index.php?view=article\&id=437\%3Ares-tse-14550-94-proppartida-tv-uso-Libras\&format=pdf\&option=com_content\&Itemid=72>. Acesso em: 18 ago. 2013.

LIMA, Ademar B. Ferreira; ROSELL, Avenir. Vocabulario de términos estenológicos. Montevideo: Impresora Cordón, 1977.

MACHADO, Flávia Oliveira. Comunicação acessível para o desenvolvimento inclusivo: a política de acessibilidade na televisão brasileira. In: Colóquio Internacional da Escola Latinoamericana de Comunicação, 15., 2011, Araraquara. Anais eletrônico... Araraquara: UNESP, 2011. Disponível em: <http://celacom.fclar.unesp.br/pdfs/49.pdf>. Acesso em: 18 ago. 2013.

NASCIMENTO, Marcus Vinícius Batista. Interpretação da Libras no gênero jornalístico televisivo: elementos extralinguísticos na produção de sentidos. In: Congresso Nacional de Pesquisas em Tradução \& Interpretação de Libras e Língua Portuguesa, 2., 2010. Anais 
eletrônicos... Disponível em:

<http://www.congressotils.com.br/anais/anais2010/Ariane\%20Rafaela\%20de\%20Freitas.pdf> . Acesso em: 5 ago. 2013.

REICHERT, André Ribeiro. Mídia televisiva sem som. 2006. 100f. Dissertação (Mestrado em Educação) - Universidade Federal do Rio Grande do Sul, Porto Alegre, 2006.

SERRA, J. Paulo. Manual de teoria da comunicação. Covilhã: Labcom, 2007.

VIGATA, Helena S; BARBOSA, Lúcia M. A. Quem arrancou essa planta do meu jardim? Argumentos a favor do uso de legendas interlinguais no ensino de língua estrangeira.

Horizontes de Linguística Aplicada, Brasília, v. 8, n. 2, 2009, p. 220-237. Disponível em: <http://periodicos.unb.br/index.php/horizontesla/article/view/2943/2547>. Acesso em: 21 out. 2013. 